\title{
New Boron-Containing Materials for Surface Hardening
}

\author{
Fedor Panteleyenko ${ }^{1,4^{*}}$, Oleg Ostanin ${ }^{2}$, Katerina Panteleyenko ${ }^{1}$ and Grigory Petrishin ${ }^{3}$ \\ ${ }^{1}$ Belarusian national technical university, 220013, Minsk, 65 Nezavisimosty ave., Republic of Belarus \\ ${ }^{2}$ T.F. Gorbachev Kuzbass State Technical University, 650000 Kemerovo, 28 Vesennya st., the \\ Russian Federation \\ ${ }^{3}$ Sukhoi State Technical University of Gomel, 246746, Gomel, 48 Prospect Octiabria, Republic of \\ Belarus \\ ${ }^{4}$ The John Paul II Catholic University of Lublin, 37-450, Stalowa Wola, ul. Ofiar Katynia 6a, Poland
}

\begin{abstract}
The authors propose the range of new materials for restoring and strengthening coatings deposition, which have the next advantages: they are made of dispersive metal wastes (allows solve the problem of waste recycling), inexpensive, doesn't require special equipment and expensive expendables, provides high adhesion to the steel underlay, high wear resistance and low porosity. The microstructure and the main regularities in coatings obtained of these new materials via different methods are researched and described in this paper. Based on this, the main recommendations in applying area for these coatings can be formulated. Industrial testing of such coatings confirmed their high exploitation properties. New materials can be applied for restoring and strengthening of metallurgical equipment, agricultural tillage and forage machines, elements of constructing machines metal parts.
\end{abstract}

\section{Introduction}

Nowadays technologies of metal parts restoring and surface hardening are widely spread because of their economic efficient: in general, it is rather cheaper to deposit functional surface layer with any properties required (wear resistance, corrosion resistance, hardness, etc.) on the detail made of the ordinary structural steel. Thus, modern industry is very interested both in handy fast coatings deposition methods development and inexpensive, but qualitative materials for these coatings.

The main issues which minds a manufacturer while choosing deposition method and material for deposition are the following: to use common multipurpose equipment; less extra expensive expendables; materials for deposition, which provide quality, high exploitation properties and adhesion of coating to underlay. All these requirements are met by the new material developed by the authors. This paper is devoted to the research of structure and properties of new self-protecting powders on the base of dispersion metal wastes for coatings deposition and functional coatings made of them via different methods.

\footnotetext{
*Corresponding author: panteleyenko@inbox.ru
} 
So, one more advantage of this material is that the problem of metal wastes utilization can be solved.

\section{Materials for surface hardening}

Above-mentioned requirements to the new materials and technology of their deposition are carried out by self-protecting effect of new powders. As a raw material for getting of these materials for deposition the wastes of steel and cast iron fraction production were used. These are small particles of sphere or irregular shape with size $1 \mathrm{~mm}$ and less (fig.1, a, b).

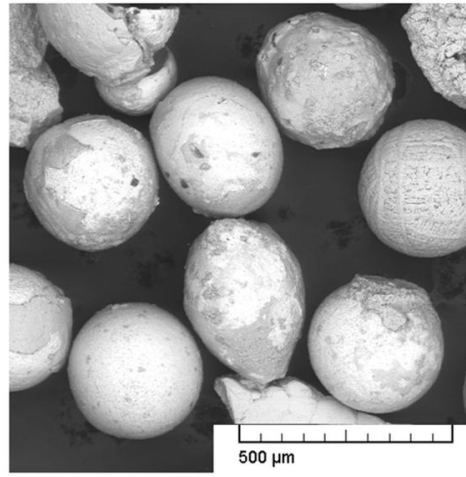

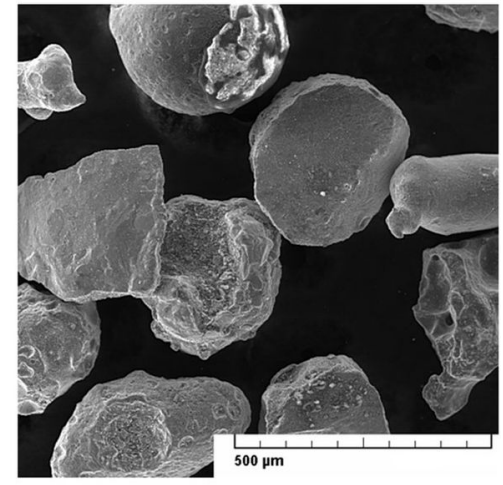

Fig.1. Morphology of the raw powder: $a$ - steel particles; $b$ - cast iron particles

Steel particles are characterized with quenching structure (martensite). Particles of cast iron have hypoeutectic white cast iron structure. It is caused by technology of production: melted drops of dispersed alloy are cool down in the water with high speed.

To make the powder self-protecting during coating deposition these raw materials were diffusional alloyed with boron. Addition of boron allows avoid the oxidation of ferrous alloy and to get rid of oxide insertions in the coatings while particle melts during deposition.

Industry produces two types of self-fluxing powders for surface hardening technologies. The first ones are the Ni-based powders, which provide high hardness, wear and corrosion resistance. At the same time, these materials are rather expensive. Mainly parts of the deposit coatings are made of steel, nickel-based alloy and steel and have different thermo physical properties - that can lead to coatings cracking and exfoliation. Moreover, sometimes there is no need to get such complex of properties. Another group - are Febased powders doped with boron, produced via spraying of boron alloyed steel melt. Powders perfectly provide self-protection properties, but all boron spends while deposition for self-fluxing process. The main drawback of these powders is inability of boron concentration regulation $-9 \mathrm{wt} \%$ is maximal amount in most widely manufactured by industry powders [1-3]. There are some types of powders producible which can contain up to $18 \mathrm{wt} \%$ of boron, but they are rather expensive. Boron concentration increasing is preferable because of the hard $\mathrm{Fe}_{\mathrm{x}} \mathrm{B}_{\mathrm{y}}$ phases in coatings structure providing higher exploitation properties.

Due to the production technology (chemical-thermal treatment in $\mathrm{B}_{4} \mathrm{C}$ powder) $[4,5]$ the new powders made of fraction wastes are characterized with concentration up to 15 weight $\%$ of boron $[3,6]$. The last one gets into the coatings structure as micro inclusions of FeB and $\mathrm{Fe}_{2} \mathrm{~B}[6,7]$. Distribution of these very hard phases with micro hardness $19500 \div 21000$ 
$\mathrm{MPa}$ and $13800 \div 14.500 \mathrm{MPa}$ respectively in more plastic and soft matrix forms heterogeneous coatings with unique exploitation properties $[6,7,8]$. Such layers combine high wear resistance, excellent adhesion and cracking resistance. Besides the layers and underlay have the similar thermo physical properties, what prevents coating exfoliation.

Along with the use of aluminium oxide and diamonds $[9,10]$, the high efficiency of using self-fluxing boron powders as materials for magneto-abrasive treatment has been established [11].

Besides self-fluxing powders on the base of fraction wastes, authors used mixtures with another disperse wastes, e.g. hard alloy shavings (tungsten-cobalt alloy containing 3\% cobalt, the basis of which is tungsten carbide) [12].

\section{Hardening coatings}

The range of proposed materials with dispersion $60 \ldots 630 \mu \mathrm{m}$ can be used in such technologies as magneto-electric welding, induction cladding [13], electric arc welding with non-consumable electrode.

Using these technologies a wide range of coatings were received, researched and put to the testing in industry.

The main regularities in coatings received are the following:

1. The structure of coating (hypoeutectic, eutectic or hypereutectic) depends on boron concentration in initial powder and on the method of deposition. Data in table 1 describe this regularity on the example of cast iron boronized powder.

Table 1. Structure dependence on boron concentration in powder deposited.

\begin{tabular}{|c|c|c|c|}
\hline \multirow{2}{*}{$\begin{array}{c}\text { Method of coating } \\
\text { deposition }\end{array}$} & \multicolumn{2}{|c|}{ Boron concentration required in order to receive structure } \\
\cline { 2 - 4 } & hypoeutectic & eutectic & hypereutectic \\
\hline $\begin{array}{c}\text { magneto-electric } \\
\text { welding }\end{array}$ & Less $12 \pm 0.5 \mathrm{wt} \%$ & $12 \pm 0.5 \mathrm{wt} \%$ & More $12 \pm 0.5 \mathrm{wt} \%$ \\
\hline Induction cladding & Less $7.3 \pm 0.5 \mathrm{wt} \%$ & $7.3 \pm 0.5 \mathrm{wt} \%$ & More $7.3 \pm 0.5 \mathrm{wt} \%$ \\
\hline electric arc welding & Less $13 \pm 0.5 \mathrm{wt} \%$ & $13 \pm 0.5 \mathrm{wt} \%$ & More $13 \pm 0.5 \mathrm{wt} \%$ \\
\hline
\end{tabular}

The structure of coatings received via all of deposition methods mentioned is similar. It is clearly seen at fig.2, 3. The number of rounder dendritic inclusions in hypoeutectic coatings depends on boron concentration: the less boron contained, the larger the number. The microhardness of inclusions is from 4000 to $4400 \mathrm{MPa}$. It is higher, than perlite has, and caused by boron. 


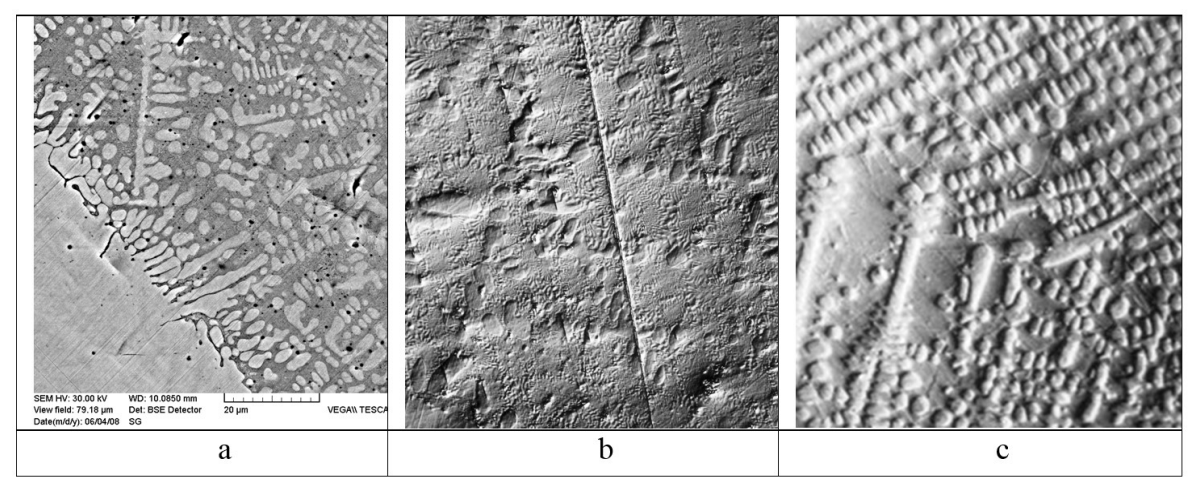

Fig.2. Hypoeutectic coating's structure: a - magneto-electric coating; b - induction cladding coating; c- electric arc welding coating, (x1000).

Hypereutectic coatings are characterized with angular inclusions of $\mathrm{Fe}_{\mathrm{x}} \mathrm{B}_{\mathrm{y}}$ of irregular shape - they are clearly seen in all structures at fig.3. Their hardness is from 17880 to $22360 \mathrm{MPa}$ and corresponds to FeB hardness.

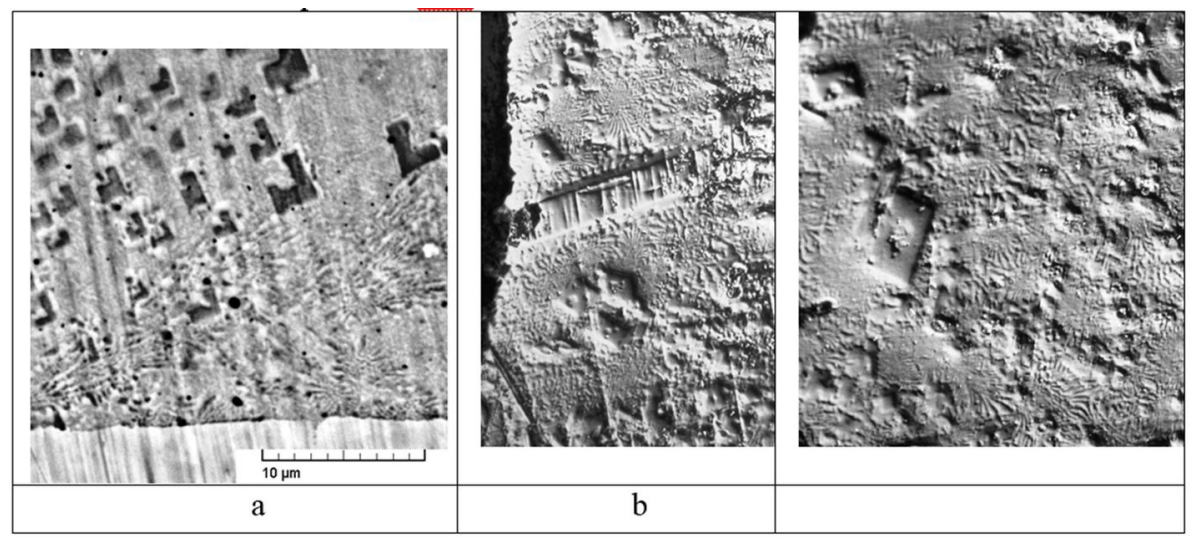

Fig.3. Hypereutectic coatings structure: a - magneto-electric coating; b - induction cladding coating; c- electric arc welding coating

Classical structure of boride fan-shaped eutectic is on the fig.4 


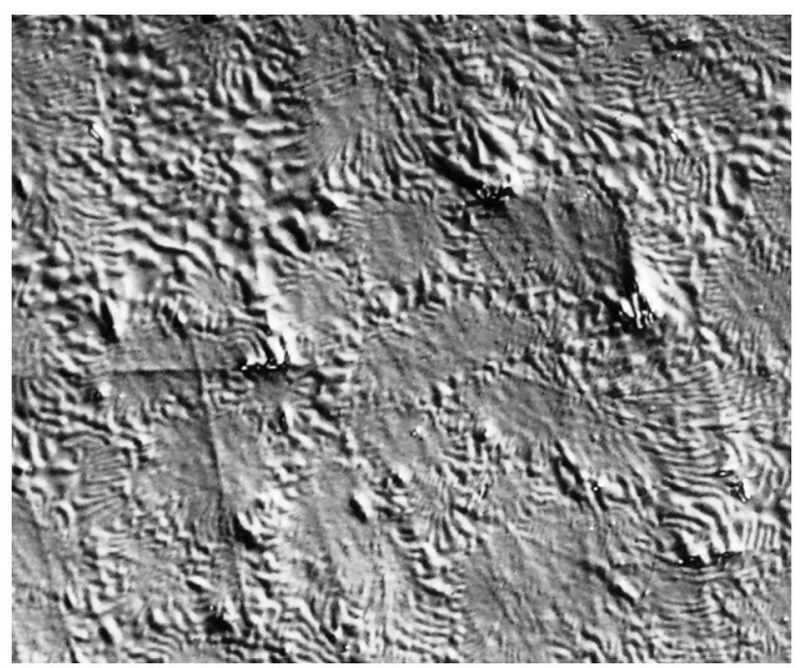

Fig.4. Eutectic structure

2. The coatings received have low porosity, absence of oxide inclusions in structure, qualitative fusion zone with the substrate that provides high quality and adhesion. It should be noted, that for induction cladding using of large size fractions is preferable, because of insufficient melting of tiny particles under high frequency currents treatment.

3. Eutectic structure provides the best wear resistance under sliding friction without lubrication conditions. Homogeneous stricture without any hard inclusions is preferable. However, for the exploitation under abrasive and impact-abrasive wear conditions hypereutectic structure is better, because of matrix plasticity and inclusion's hardness combination. So, the more boron, the higher wear resistance under impact-abrasive wear conditions is.

\section{Coatings testing}

After laboratory testing, new hardening coatings were tested under industrial condition of work. The new coatings are implemented for restoring and hardening of machine parts which during work process contact another metal parts of mechanisms, manufacturing products (wire) or abrasive materials (sand, soil with small stones, liquids with abrasive particles) [14]. These are parts of metallurgical equipment, agricultural tillage and forage machines, elements of constructing machines [15]. According to regularities discovered and described the basic feature we guided by the working conditions of the part for hardening: whether is sliding friction or abrasive and impact-abrasive wear.

Testing showed service life period increasing in 2-4.2 times in comparison with nonstrengthened initial machine parts. As an example at fig.5 is a restored detail - end part of feeder screw for building materials manufacture. 


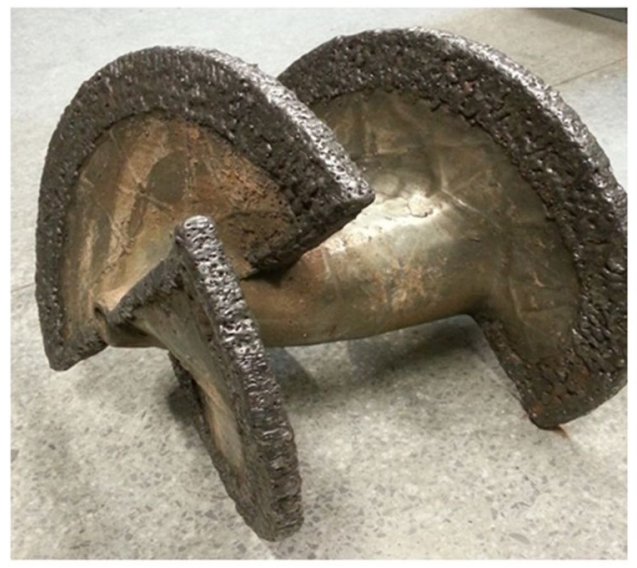

a

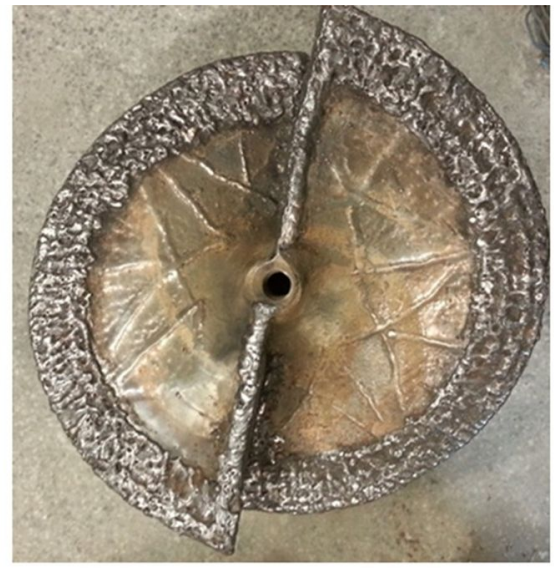

b

Fig.5. Restored end part of feeder screw for building materials manufacture: $a, b$ - view from different sides

It should be noted, that not only pure new materials, but their mixtures with commercially available powders can be used for restoring and hardening. For instance, mixtures of new self-fluxing Fe-based powders with Ni-based self-fluxing powders or with another disperse metal waste products (hard alloy shavings) are successfully used. By this way the problem of wastes recycling and getting cheap high-quality coatings can be solved.

\section{References}

1. Powders from alloys for surfacing. Specifications: GOST 21448 (Moscow: State Standard of the USSR, 1975)

2. A.I. Sidorov, Restoration of machine parts by spraying and surfacing (Moscow: Engineering, 1987)

3. F.I. Panteleyenko, Self-fluxing diffusion-alloyed Fe-based powders and protecting coatings made of them (Minsk, Technoprint, 2001)

4. L.G. Voroshnin, L.S. Lyahovich, Boriding of steel (Moscow, Metallurgy. 1978)

5. S.N. Lubetsky, Development of technology of diffusion alloying of iron powders and production of surfaced wear-resistant coatings (Minsk, 1991)

6. E.F. Panteleyenko, Self-fluxing composite powders from borated waste steel and cast iron shot for magnetic electric hardening and restoration of machine parts: PhD. thesis (Minsk, 2009)

7. G.V. Petrishin, Heterogeneous wear-resistant coating of borated alloying material based on waste steel shot, applied magnetic-electric method: PhD. thesis (STU of Gomel - Gomel, 2006)

8. E.F. Panteleyenko, Materials of VII International scientific and practical conference "Surface engineering of machine parts", 227 (2009)

9. K. Hanada and H. Yamaguchi, Advanced Materials Research, 75, 43 (2009)

10. K. Hanada, H. Yamaguchi and H. Zhou, Diamond and related materials, 17, 1434 (2008)

11. F.I. Panteleyenko, G.V. Petrishin, E.F. Panteleyenko and V.M. Bystrenkov, New diffusion-borated materials for magnetic abrasive treatment. Chapter 13. Monography. Advanced materials and technologies. (Vitebsk. 2017) 
12. E.F. Panteleyenko, G.V. Petrishin, Materials of VII International scientific and practical conference "Innovations in mechanical engineering", 355 (2015)

13. E.F. Panteleyenko, Foundry Production and Metallurgy, 3:66, 114 (2012)

14. G. V. Petrishin, V. M. Bystrenkov, E.F. Panteleyenko, Materials of «Belagro-2013», (2013)

15. G.V. Petrishin, V.M. Bystrenkov, V I. Odarchenko, Materials of 26th conference, (2018) 